\title{
17ß-estradiol induces up-regulation of PTEN and PPAR $\gamma$ in leiomyoma cells, but not in normal cells
}

\author{
YOUNG-JU JEONG ${ }^{1 *}$, EUN-MI NOH ${ }^{2 *}$, YOUNG-RAE LEE ${ }^{2}$, HONG-NU YU ${ }^{2}$, KYU-YUN JANG ${ }^{3}$, \\ SEUNG JIN LEE ${ }^{4}$, JONGHYEON KIM ${ }^{1}$ and JONG-SUK KIM ${ }^{2}$ \\ Departments of ${ }^{1}$ Obstetrics and Gynecology, ${ }^{2}$ Biochemistry and Institute for Medical Sciences and ${ }^{3}$ Pathology, \\ Chonbuk National University Medical School, Jeonju 561-180; ${ }^{4}$ Department of Pharmacy, \\ College of Phamacy, Ewha Womans University, Seoul 120-750, Korea
}

Received November 13, 2009; Accepted January 25, 2010

DOI: 10.3892/ijo_00000571

\begin{abstract}
The tumor suppressor protein, PTEN (phosphatase and tensin homologue), has been reported to play a crucial role in a variety of tumor cells. Recent studies indicate that the transcription factor, PPAR $\gamma$ (peroxisome proliferatoractivated receptor $\gamma$ ) up-regulates PTEN expression transcriptionally through the binding of two response elements in the genomic sequence upstream of PTEN in tumor cells. Here, we determined the PTEN and PPAR $\gamma$ expression in human leiomyomas, and whether estrogen can change their protein expressions in cultured leiomyoma cells. Immunohistochemical staining and Western blot analysis revealed that PTEN protein levels in leiomyomas were higher than that the adjacent normal myometrial tissues, which was paralleled with decrease in phospho-Akt (ser-473) and phosphatidylinositol 3,4,5-tris phosphate $\left(\mathrm{PIP}_{3}\right)$ level. Interestingly, leiomyomas exhibit high PPAR $\gamma$ expression compared to the adjacent normal myometrial tissues. In addition, we found that $17 ß-$ estradiol (E2) significantly stimulated PTEN and PPAR $\gamma$ expression in cultured leiomyoma cells, but did not change both protein levels in normal cells. This report shows the first evidence that PTEN and PPAR $\gamma$ are up-regulated in leiomyoma tissues, and estrogen stimulates expression of PTEN and PPAR $\gamma$ in leiomyoma cells, but not in normal cells.
\end{abstract}

Correspondence to: Dr Jonghyeon Kim, Department of Obstetrics and Gynecology, Chonbuk National University Medical School, Jeonju 561-180, Korea

E-mail: hyeon69@jbnu.ac.kr

Dr Jong-Suk Kim, Department of Biochemistry and Institute for Medical Sciences, Chonbuk National University Medical School, Jeonju 561-180, Korea

E-mail: jsukim@chonbuk.ac.kr

*Contributed equally

Key words: PTEN, PPAR $\gamma$, estradiol, uterine leiomyoma

\section{Introduction}

PTEN on chromosome 10q23 has been recognized as one of the major tumor suppressor genes in human cancers. PTEN is also called MMAC1 (mutated in multiple advanced cancers), and TEP1 (TGF-ß-regulated and epithelial cell-enriched phosphatase) (1,2). Mutations and/or deletions in PTEN are found in a variety of cancer cells, including endometrial, breast, ovarian, and lung neoplasia (3-7). Germline mutations in PTEN are also found in inherited harmatoma tumor syndromes such as Cowden's syndrome, which has a high risk of breast, thyroid and other tumors (8). Mechanisms by which the expression of PTEN is regulated are, however, unclear. Recently it has been known that PPAR $\gamma$ is able to bind two response elements in the genomic sequence upstream of PTEN (9), indicating that PPAR $\gamma$ can control PTEN expression transcriptionally in tumor cells.

Uterine leiomyomas, also called fibroids, are the most common reproductive tract neoplasm and the leading indication for hysterectomy in premenopausal women. These tumors are the leading indication for hysterectomy in the world $(10,11)$. Currently, there is no effective medical treatment option for this condition, hysterectomy is the mainstay of management. This is not an attractive choice for many women, especially patients desiring to preserve their fertility potential. However, the development of medical therapies for uterine leiomyoma has been hampered by a lack of understanding regarding the etiology and molecular mechanisms underlying the development of these lesions. Although the incidence of this neoplasm is extremely high, the etiology has remained elusive.

The growth of reproductive organ during pregnancy and the menstrual cycle such as uterine endometrium is dependent on estrogen. It has been thus expected that proliferative activity of estrogen on normal cells be considered as a stimulant for the initiation and promotion of tumors in these organs. Many risk factors associated with tumor development have been identified from epidemiologic studies, including obesity, age, race, and unopposed estrogen exposure (12-22). The hormonal dependence of leiomyoma growth is indicated by the fact that most of these tumors are diagnosed during the reproductive years, increase in size during pregnancy, 
and regress after the onset of menopause (10), and events that all coincide with changes in hormonal milieu. Other evidence supporting estrogen dependence of uterine leiomyomas are the increased estrogen receptor (ER) expression and decreased E2 metabolism observed in these tumors (23). Consequently, the growth of uterine leiomyomas is thought to be modulated by the ovarian hormones estrogen (E2) and progesterone.

The progression of the neoplastic state is influenced by deregulation of oncogenes or inactivation of tumor suppressors (24). It is known that endometrial expression of PTEN is not constant throughout the menstrual cycle, but changes in response to the hormonal environment $(25,26)$. Although sex steroid hormones have been shown to regulate PTEN, little is known concerning PTEN expression in uterine leiomyoma. The present study therefore was conducted to elucidate the PTEN expression in human leiomyomas and its regulation by estrogen.

\section{Materials and methods}

Materials. Antibodies against PTEN, p53, ß-actin, myosin, and ER $\alpha$ were purchased from Santa Cruz Biotechnology (Santa Cruz, CA, USA). Antibodies against p-Akt (ser-473), p-PTEN (ser-385), and Akt were purchased from Cell Signaling (Beverly, MD, USA). Fetal bovine serum (FBS) and charcoal-dextran treated FBS were obtained from Gibco BRL (Life Technologies, Inc., Grand Island, NY, USA). HBSS (Hanks balanced salt solution), 17-ß-estradiol (E2), DMEM, phenol red-free DMEM obtained from Sigma Chemical Co. (St. Louis, MO, USA).

Tissue collection. Twenty uterine leiomyomas and the adjacent normal myometrial tissues were collected from different patients. The patients ranged in age from 30 to 45 years and underwent hysterectomy for medically indicated reasons at Chonbuk National University Hospital. Histological diagnosis of each uterine specimen was determined by a pathologist. This study had local ethics committee approval obtained from the Chonbuk National University Hospital's institutional review board. Informed consent was provided according to the Declaration of Helsinki.

Immunohistochemical staining for PTEN protein. Uterine tissue specimens were fixed in $4 \%$ buffered neutral formaldehyde solution, dehydrated, and embedded in paraffin. Sections, 5-6 $\mu \mathrm{m}$ thick, were deparaffinized and followed by standard histological techniques. The avidin/biotin immunoperoxidase staining method was performed with the use of a polyvalent immunoperoxidase kit (Omnitags, Lipshow, MI). A mouse monoclonal antibody to human PTEN protein was used at a dilution of 1:200 as the primary antibody in this study. To assure the specificity of the immunological reaction, control sections were subjected to the same immunoperoxidase method, except that the primary antibody was replaced by non-immune murine IgG (Miles, Elkhart, IN) at the same dilution as the specific primary antibody.

Cell culture. Uterine leiomyoma tissues were cut into small pieces and digested in $0.2 \%$ collagenase $(\mathrm{wt} / \mathrm{vol})$ at $37^{\circ} \mathrm{C}$ for
3-5 h as previously described (24). The leiomyoma cells were collected by centrifugation at $460 \mathrm{x}$ g for $5 \mathrm{~min}$ and washed three times with DMEM containing $1 \%$ antibiotic solution. Cell viability was determined by trypan blue exclusion test. The isolated leiomyoma cells were plated at density of $\sim 10^{6}$ cells/dish in $10-\mathrm{cm}^{2}$ culture dishes and then subcultured for $120 \mathrm{~h}$ at $37^{\circ} \mathrm{C}$ in a humidified atmosphere of $5 \% \mathrm{CO}_{2}-95 \%$ air in phenol red-free DMEM supplemented with $10 \%$ FBS (vol/vol; Life Technologies, Inc.).

Protein extraction and Western immunoblotting. Leiomyomas and the adjacent normal myometrial tissues for protein extraction were collected immediately after hysterectomy. These tissue samples were homogenized at $4^{\circ} \mathrm{C}$ in the presence of lysis buffer. Homogenates were subsequently centrifuged at 13,000 x g for $30 \mathrm{~min}$, and the supernatants were collected. After washing with phosphate buffered saline (PBS), cultured cells were lysed with the lysis buffer (20 mM HEPES pH 7.2, $1 \%$ Triton X-100, $150 \mathrm{mM} \mathrm{NaCl}, 0.1 \mathrm{mM}$ phenylmethylsulfonyl fluoride (PMSF), $1 \mathrm{mM}$ EDTA, $1 \mu \mathrm{g} / \mathrm{ml}$ aprotinin). The protein concentration was determined using protein assay kits (Bio-Rad Laboratories, USA). Samples (50 $\mu \mathrm{g}$ ) were prepared with four volumes of $0.5 \mathrm{M}$ Tris buffer $(\mathrm{pH}$ 6.8) containing $4 \%$ SDS, $20 \%$ glycerol and $0.05 \%$ bromophenol blue at $95^{\circ} \mathrm{C}$ for $5 \mathrm{~min}$. SDS-PAGE was performed in $10 \%$ slab gels. Proteins were then transferred to nitrocellulose paper. Blots were incubated with the primary antibodies against protein followed by peroxidase-conjugated secondary antibody. The antigen-antibody complexes were detected with the enhanced chemiluminescence detection kit (ECL, Amersham Pharmacia Biotech).

Reverse transcription polymerase chain reaction ( $R T-P C R)$ for PTEN. RT-PCR was performed using RNA PCR kits (GeneAmp, Applied Biosystems, USA). Total RNA was isolated from cells using TRIzol reagent following the manufacturer's instructions. Five micrograms of total RNA was transcribed into cDNA in a $20 \mu$ l final volume of reaction buffer (10 mM Tris- $\mathrm{HCl}, 50 \mathrm{mM} \mathrm{KCl}, 1.5 \mathrm{mM} \mathrm{MgCl}, 1 \mathrm{mM}$ each dNTP) and $2.4 \mu \mathrm{M}$ oligo-d(T)16-primer, $1 \mathrm{U}$ RNase inhibitor, and 2.5 U M-MLV RNase H-reverse transcriptase by incubation for $15 \mathrm{~min}$ at $70^{\circ} \mathrm{C}$ and $50 \mathrm{~min}$ at $42^{\circ} \mathrm{C}$. The reaction was stopped by incubation at $95^{\circ} \mathrm{C}$ for $10 \mathrm{~min}$. PCR aliquots of the synthesized cDNA were added to a $45-\mu 1$ PCR mixture containing $10 \mathrm{mM}$ Tris- $\mathrm{HCl}, 50 \mathrm{mM} \mathrm{KCl}, 1.5 \mathrm{mM}$ $\mathrm{MgCl}_{2}, 0.2 \mathrm{mM}$ each dNTP, and $2 \mathrm{U}$ Taq DNA polymerase, and $0.4 \mu \mathrm{M}$ of each PCR primer: sense primer, human PTEN (5'-CCGGAATTCATGACAGCCATCATCAAAGA-3'), and antisense primer, human PTEN (5'-CGCGGATCCTCAGA CTTTTGTAATTTGTG-3'). Amplification for PTEN was initiated with $3 \mathrm{~min}$ of denaturation at $94^{\circ} \mathrm{C}$ followed by 26 cycles at $94^{\circ} \mathrm{C}$ for $1 \mathrm{~min}, 94^{\circ} \mathrm{C}$ for $1 \mathrm{~min}, 55^{\circ} \mathrm{C}$ for $1 \mathrm{~min}$, and $72^{\circ} \mathrm{C}$ for $3 \mathrm{~min}$. After the last cycle of amplification, the samples were incubated for $5 \mathrm{~min}$ at $72^{\circ} \mathrm{C}$. $\beta$-actin PCR was performed with $2.5 \mu \mathrm{l}$ aliquots of synthesized cDNA using primers at a concentration of $0.15 \mu \mathrm{M}$ : sense primer, human B-actin (5'-CCACGAAACTACCTTCAAC TCC-3'), antisense primer (5'-TCATACTCCTGCTGCTTGCTGA TCC-3'). The obtained PCR products were analyzed on ethidium bromide-stained agarose gels (2\%). 
A
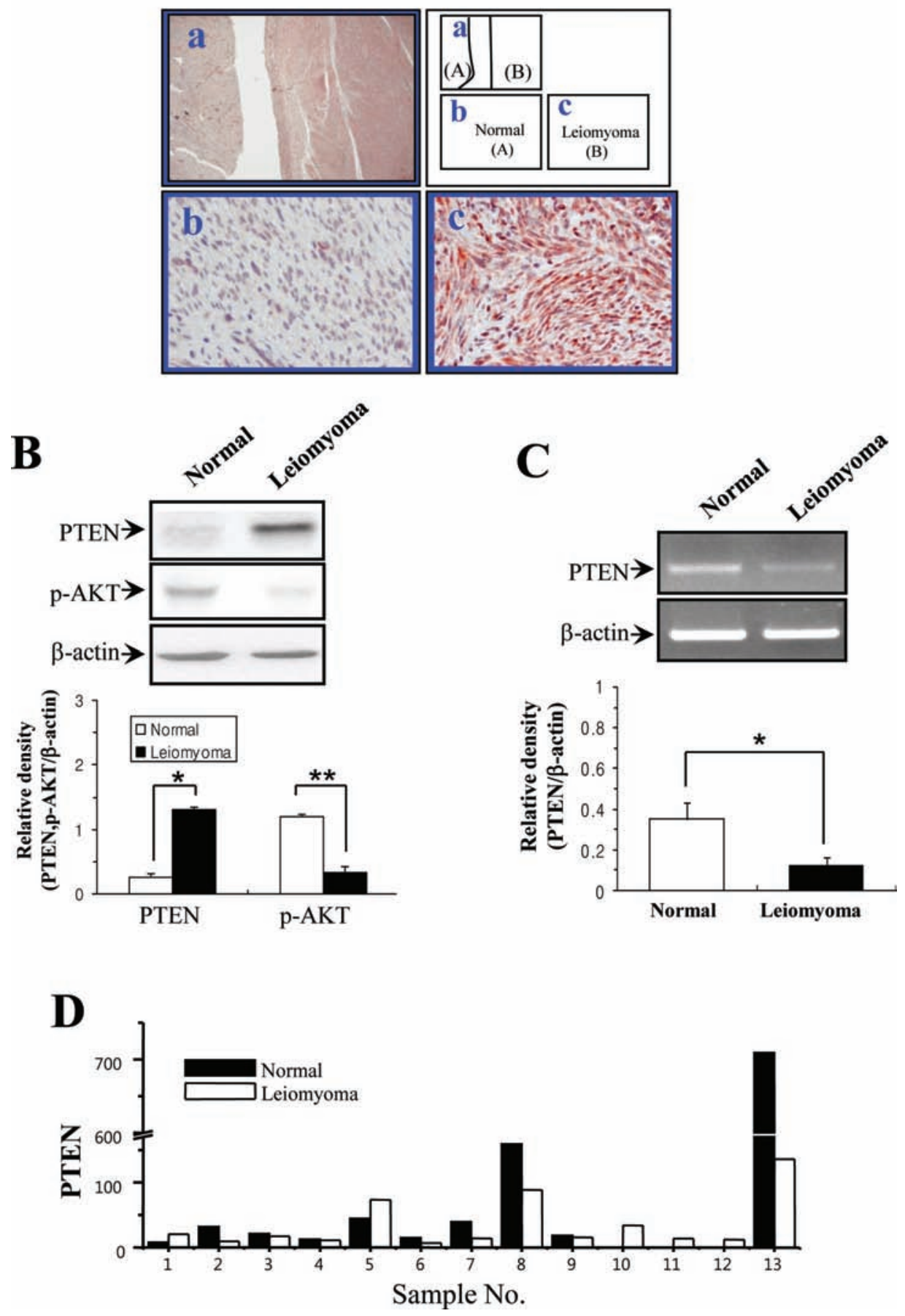

Figure 1. PTEN expression of human uterine leiomyoma and the adjacent normal myometrial tissues. (A) Immunohistochemical staining for PTEN in formalin-fixed paraffin-embedded sections in human uterine myometrium in the whole tissues (a) the adjacent normal myometrial tissues (b), the leiomyoma tissues (c). PTEN protein was immunolocalized to the cytosols of leiomyoma cells. PTEN content was high in leiomyoma compared to normal tissues. Original magnifications $\mathrm{x} 40$ (a), x400 (b and c). (B) Western blot analysis for PTEN and p-AKT contents of human uterine leiomyoma and the adjacent normal myometrial tissues. The tissue lysates were analyzed with Western blots for PTEN and p-AKT. Values were expressed as retative density of each protein to actin. The PTEN content in leiomyoma was higher than in the normal tissues, but p-AKT in leiomyoma was less than in the normal tissues. B-actin was used as a loading control. (C) The study of PTEN mRNA expression in uterine leiomyoma was analyzed by reverse transcription-polymerase chain reaction (RT-PCR). The tissue lysates were analyzed with RT-PCR for PTEN. Values were expressed as retative density of PTEN to actin. The PTEN mRNA content in leiomyoma was less than in the normal tissues. B-actin was used as a loading control. (D) Quantitative polymerase chain reaction (real time-PCR) in the determination of expression levels of selected genes in leiomyoma. The tissue lysates (sample no. 13) were analyzed with real time-PCR for PTEN mRNA. Error bars, $\mathrm{SD} ; \mathrm{n}=20$ in each group. ${ }^{*} \mathrm{P}<0.002 ;{ }^{* *} \mathrm{P}<0.005$ compared with normal.

Real-time quantitative reverse transcription-polymerase chain reaction for PTEN. Real-time PCR was performed using a LightCycler rapid thermal cycler system (Roche Diagnostics
Ltd., Lewes, UK) according to the manufacturer's instructions. Total RNA was isolated from tissues using TRIzol reagent (Life Technologies Ltd., Paisley, UK). RNA was isopropanol 
precipitated, dissolved in DEPC-treated distilled water and kept at $-80^{\circ} \mathrm{C}$ until use. RNA $(1 \mu \mathrm{g})$ was reverse transcribed with Superscript II reverse transcriptase (Life Technologies Ltd.). The cDNA was diluted 10-fold prior to PCR amplication. The oligonucleotide primers used for PCR are as follows: PTEN upstream 5'-CCACAGCTAGAACTTATCAAACC-3', downstream 5'-ATGAACTTGTCTTCCCGT-3'. E 2 F upstream 5'-TGGGAAGAAGGAGGACCTCTA-3', E 2 F downtream 5'-TTCATCACCCGCATGTTG-3'. Reactions were performed in a $20-\mu 1$ volumed with $0.5 \mu \mathrm{M}$ primers and $\mathrm{MgCl}_{2}$ concentration optimized between 2-5 mM. Nucleotides, Taq DNA polymerase, and buffer were included in the LightCycler-DNA Master SYBR Green I mix (Roche Diagnostics Ltd.). PCR amplication began with a 10 -min per-incubation step at $95^{\circ} \mathrm{C}$, followed by 45 cycles of denaturation at $95^{\circ} \mathrm{C}$ for $10 \mathrm{sec}$, annealing at $56^{\circ} \mathrm{C}(\mathrm{PTEN})$ or $55^{\circ} \mathrm{C}\left(\mathrm{E}_{2} \mathrm{~F}\right)$ for $5 \mathrm{sec}$, and elongation at $72^{\circ} \mathrm{C}$ for $10 \mathrm{sec}$. The relative concentration of PCR product derived from the target gene (PTEN) was calculated using software of the LightCycler System. A standard curve for each run was constructed by plotting the crossover point against the log (number of starting molecules). The number of target molecules in each samples was then calculated automatically by reference to this curve. Results were expressed relative to the number of $\mathrm{E}_{2} \mathrm{~F}$ transcripts used as an internal control. All experiments were performed in triplicate.

Immunohistochemical methods for $\mathrm{PIP}_{3}$ analysis. The intracellular $\mathrm{PIP}_{3}$ level was directly determined by an immunohistochemical method using a recent developed monoclonal antibody to $\mathrm{PIP}_{3}$ as described by Niswender et al (27). Slide glasses containing tissue specimens were equilibrated in PBS at room temperature. The tissues were fixed for 5-10 min (room temperature) in 4\% paraformaldehyde. After blocking in $5 \%$ normal goat serum (NGS) and $2 \%$ bovine serum albumin (BSA), samples were incubated with mouse anti-PIP $\mathrm{P}_{3}$ monoclonal antibody (Echelon) at a 1:100 dilution overnight at $4^{\circ} \mathrm{C}$. The negative immune control for antibody was an equivalent concentration of non-immune mouse IgM. Primary antibodies were detected with goat anti-mouse IgM-TRITC at a 1:200 dilution $1 \mathrm{~h}$ at $4^{\circ} \mathrm{C}$. Samples were mounted in aqueous mounting medium with anti-fading agents. Images were acquired with an Axiovert S100 fluorescence microscope (Zeiss) equipped with a DP70 digital camera (Olympus).

Statistical analysis. The t-test was used to determine the statistical significance of the data obtained and to compare the means of the two groups. One-way ANOVA and StudentNewman-Keuls test was used for multiple comparisons. $\mathrm{P}<0.05$ was set as a statistically significant difference between the values of two group means.

\section{Results and Discussion}

Human uterine leiomyomas exhibit high PTEN expression compared to the adjacent normal myometrial tissues. We firstly measured PTEN expression by using immunohistochemical analysis in leiomyoma. The tumor suppressor PTEN was immunolocalized to the cytosol of leiomyoma cells. PTEN
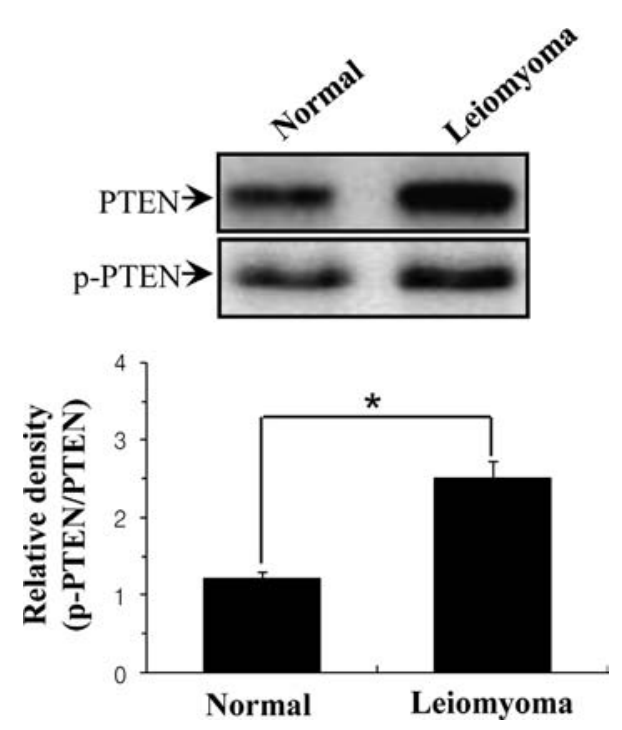

Figure 2. Western blot analysis for p-PTEN content of human uterine leiomyoma and the adjacent normal myometrial tissues. The tissue lysates were analyzed with Western blots for p-PTEN. Values were expressed as relative density of p-PTEN to actin. The p-PTEN content in leiomyoma was less than in the normal tissues. B-actin was used as a loading control. Error bars, SD; $\mathrm{n}=20$ in each group. ${ }^{*} \mathrm{P}<0.005$ compared with normal.

expression of leiomyoma tissue was higher than that of the adjacent normal myometrial tissue (Fig. 1Aa). PTEN expression level was the highest in the cytosols of leiomyoma cells than other organelles (Fig. 1Ac). Western immunoblot analysis also revealed that PTEN expression of leiomyoma tissue was higher than that of the adjacent normal myometrial tissue (Fig. 1B). However, RT-PCR and real-time PCR showed that PTEN mRNA level of leiomyoma was lower than that of the adjacent normal myometrial tissue (Fig. 1C and D). Consequently, these findings suggest that PTEN level of leiomyoma is dependent on protein stability rather than protein synthesis.

Human uterine leiomyomas exhibit high p-PTEN expression compared to the adjacent normal myometrial tissues. The phosphorylation level of PTEN protein regulates its stability (28). In particular, serine phosphorylation (ser-370 and ser-385) of PTEN assumes a closed conformation with enhanced stability (29), suggesting that high phosphorylation of PTEN (p-PTEN) cause an increase in its stability. Thus, we measured p-PTEN (ser-385) level using Western blotting in leiomyoma. As we expected, there was a clear difference in p-PTEN protein content between leiomyoma tissues and the adjacent normal myometrial tissues. p-PTEN level was significantly increased in leiomyoma tissues compared to the adjacent normal myometrial tissues (Fig. 2).

Human uterine leiomyomas exhibit low $\mathrm{PIP}_{3}$ level compared to the adjacent normal myometrial tissues. Phosphatidylinositol 3-kinase (PI3K) promotes generation of phosphatidylinositol 3,4,5, trisphosphate $\left(\mathrm{PIP}_{3}\right.$ ), which binds to Akt. $\mathrm{PIP}_{3}$-bound Akt is translocated from the cytosol to the plasma membrane, where it is activated through phosphorylation (30). PI3K signaling

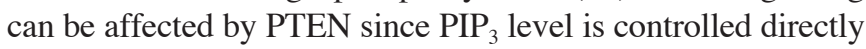




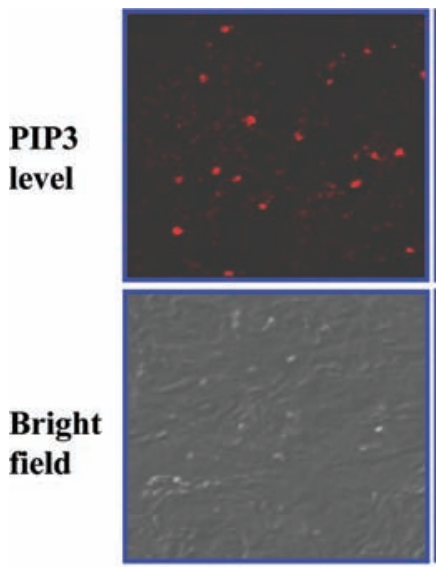

Normal
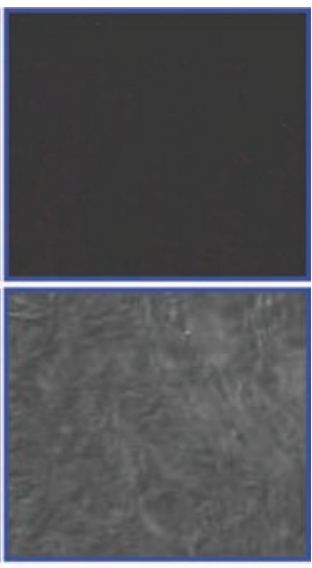

Leiomyoma
Figure 3. Immunolocalization of $\mathrm{PIP}_{3}$ in human uterine leiomyoma. Confocal laser scanning microscopy was performed for analysis of intracellular $\mathrm{PIP}_{3}$ level in leiomyoma. $\mathrm{PIP}_{3}$ level of leiomyoma was less than in the normal tissues. Tissues were visualized by confocal microscopy with a $\mathrm{x} 400$ objective.
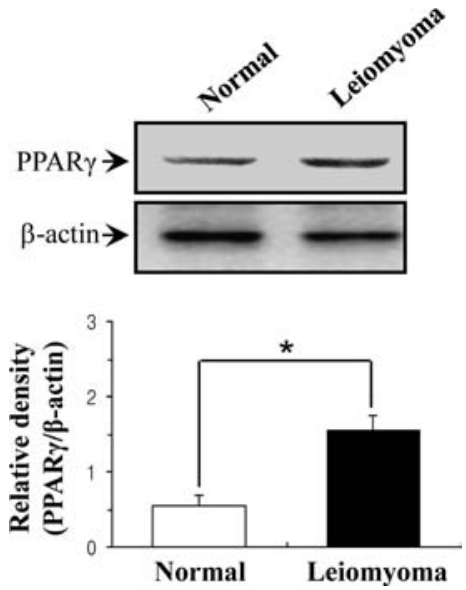

Figure 4. Western blot analysis for PPAR $\gamma$ content of human uterine leiomyoma and the adjacent normal myometrial tissues. The tissue lysates were analyzed with Western blots for PPAR $\gamma$. Values were expressed as retative density of PPAR $\gamma$ to actin. The PPAR $\gamma$ content in leiomyoma was higher than in the normal tissues. B-actin was used as a loading control. Error bars, SD; $\mathrm{n}=20$ in each group. ${ }^{*} \mathrm{P}<0.001$ compared with normal.

A

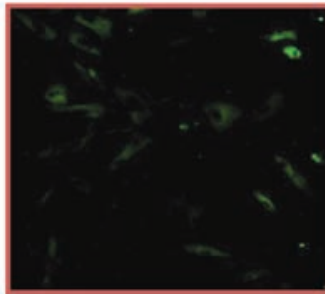

Myosin level

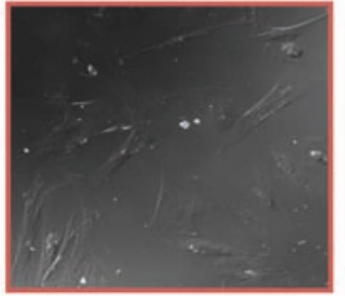

Bright field
B
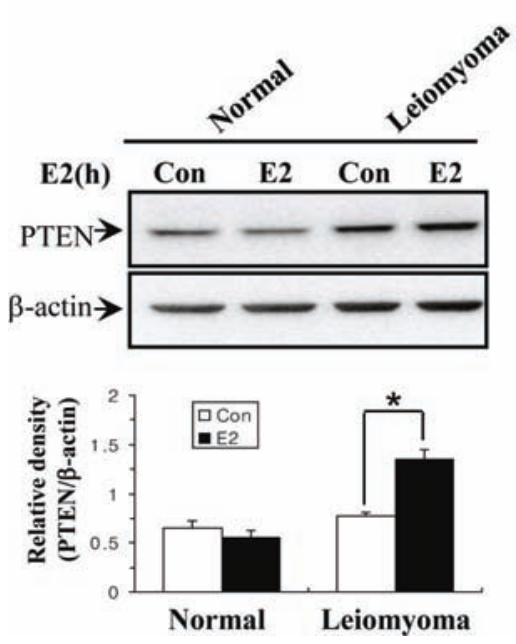

C
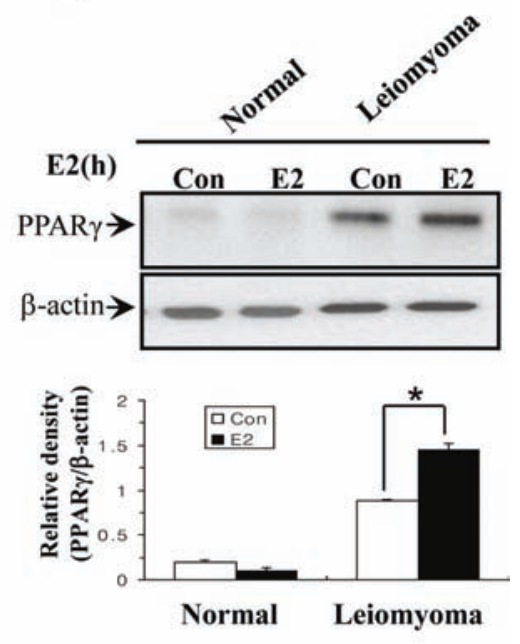

Figure 5. Effect of E2 on PTEN and PPAR $\gamma$ expression in isolated cells from human uterine leiomyoma and the adjacent normal myometrial tissues. (A) Immunolocalization of myosin in human uterine leiomyoma. Confocal laser scanning microscopy was performed for identification of smooth muscle cells. Cultured cells isolated from leiomyoma and the adjacent normal myometrial tissues showed myosin imaging. Cells were visualized by confocal microscopy with a x400 objective. (B) Effect of E2 on PTEN expression in human breast cancer MCF-7 cells. ER $\alpha$-positive MCF-7 human breast cancer cells (5x10 5 ) were treated with $10 \mu \mathrm{M}$ E2 for the indicated times. Cell lysates were analyzed with Western blots for PTEN. $\beta$-actin was used as a loading control. Human uterine leiomyoma cells or normal cells $\left(1 \times 10^{5}\right)$ were treated with $10 \mathrm{nM}$ E2 for $48 \mathrm{~h}$. Cell lysates were analyzed with Western blots for PTEN. B-actin was used as a loading control. (C) Effect of E2 on PPAR $\gamma$ expression in isolated cells from human uterine leiomyoma and the adjacent normal myometrial tissues. Human uterine leiomyoma cells or normal cells $\left(1 \times 10^{5}\right)$ were treated with $10 \mathrm{nM} \mathrm{E} 2$ for $48 \mathrm{~h}$. Cell lysates were analyzed with Western blots for PPAR $\gamma$. B-actin was used as a loading control. The analysis of electrophoretic band was performed with the LAS-1000 (Fujifilm, Japan). Values were normalized to control (no incubation) and expressed as percent of control. Error bars, $\mathrm{SD} ; \mathrm{n}=5$ in each group. ${ }^{*} \mathrm{P}<0.005$, compared with control. 
by the balance of activities between the PI3K, the synthetic enzyme of $\mathrm{PIP}_{3}$, and PTEN, the degradative enzyme of it. Consequently, PTEN directly affects cellular $\mathrm{PIP}_{3}$ and p-Akt level. In order to ascertain above findings, we measured intracellular $\mathrm{PIP}_{3}$ and p-Akt by using immunohistochemical analysis and Western blot analysis, respectively. As shown in Figs. 1B and 3, intracellular levels of $\mathrm{PIP}_{3}$ and p-Akt were decreased in leiomyoma, indicating that the PI3K signaling pathway is decreased in human uterine leiomyomas by high expression of PTEN compared to the adjacent normal myometrial tissues.

Human uterine leiomyomas exhibit high PPAR expression compared to the adjacent normal myometrial tissues. One emerging therapeutic approach to cancer treatment is the induction of growth arrest of cancer cells through ligand activation of nuclear hormone receptors (NHRs). This family includes estrogen receptors, retinoic acid receptors (RARs), retinoid $\mathrm{X}$ receptors (RXRs), and the vitamin $\mathrm{D}$ receptor. The latest member of NHR superfamily to be identified is the peroxisome proliferator-activated receptor $\gamma$, commonly known as PPAR $\gamma$ (31). This is a transcriptional factor that plays an essential role in mediating the pharmacological actions of PPAR $\gamma$ ligands, and is highly expressed in epithelial malignancies (32), indicating that PPAR $\gamma$ play a vital role in regulating the growth of human leiomyomas. It was reported that PPAR $\gamma$ induces upregulation of PTEN in various cancer cells $(9,33)$. In the next experiments, we therefore determined expression of PPAR $\gamma$ in leiomyoma tissues. As we expected, Western blot analysis showed that human uterine leiomyomas exhibited higher PPAR $\gamma$ expression compared to the adjacent normal myometrial tissues (Fig. 4).

17ß-estradiol (E2) induces upregulation of PTEN and PPAR $\gamma$ expression in human uterine leiomyoma cells. Finally, experiments were performed to elucidate PTEN and PPAR $\gamma$ regulation by estrogen. Thus, we first isolated successfully leiomyoma cells from leiomyoma tissues (Fig. 5A). Identification of smooth muscle cells was determined by confocal laser scanning microscopic imaging for myosin. In a previous study, we found that E2 increased PTEN expression in the $\mathrm{ER} \alpha$ positive breast cancer cell line, MCF-7. To investigate the ability of E2 to regulate PTEN and PPAR $\gamma$, leiomyoma cells or the adjacent normal cells were exposed to E2 (10 nM) for $48 \mathrm{~h}$, and levels of PTEN and PPAR $\gamma$ were determined. Western blot analyses revealed an increase of PTEN and PPAR $\gamma$ levels in human uterine leiomyoma cells (Fig. 5B and C). However, E2 did not affect PTEN and PPAR $\gamma$ in normal myometrial cells, indicating that E2 induces tumor-specific upregulation of PTEN and PPAR $\gamma$ in human uterine leiomyoma cells.

In conclusion, we have demonstrated that PTEN tumor suppressor content was remarkably increased in leiomyomas compared to the adjacent normal myometrial tissues. Consistent with these in vivo findings, the PTEN expression in leiomyoma cells cultured under serum-free, phenol redfree conditions was stimulated by E2, but was not affected in the normal cells.

\section{Acknowledgements}

This study was supported by the Korea Science and Engineering Foundation (M10528010003-05N2801-00310) and research funds of Chonbuk National University in 2007 (to Young-Ju Jeong).

\section{References}

1. Li DM and Sun H: TEP1, encoded by a candidate tumor suppressor locus, is a novel protein tyrosine phosphatase regulated by transforming growth factor beta. Cancer Res 57 : 2124-2129, 1997.

2. Steck PA, Pershouse MA and Jasser SA: Identification of a candidate tumour suppressor gene, MMAC1, at chromosome $10 \mathrm{q} 23.3$ that is mutated in multiple advanced cancers. Nat Genet 15: 356-362, 1997.

3. Eng C, Stratton M and Ponder B: Familial cancer syndromes. Lancet 343: 709-713, 1994.

4. Garcia JM, Silva JM and Dominguez G: Allelic loss of the PTEN region (10q23) in breast carcinomas of poor pathophenotype. Breast Cancer Res Treat 57: 237-243, 1999.

5. Liaw D, Marsh DJ and Li J: Germline mutations of the PTEN gene in Cowden disease, an inherited breast and thyroid cancer syndrome. Nat Genet 16: 64-67, 1997.

6. Vivanco I and Sawyers CL: The phosphatidylinositol 3-kinase AKT pathway in human cancer. Nat Rev Cancer 2: 489-501, 2002.

7. Weng LP, Brown JL and Eng C: PTEN coordinates G(1) arrest by down-regulating cyclin D1 via its protein phosphatase activity and up-regulating p27 via its lipid phosphatase activity in a breast cancer model. Hum Mol Genet 10: 599-604, 2001.

8. Eng C and Peacocke M: PTEN and inherited hamartoma-cancer syndromes. Nat Genet 19: 223, 1998.

9. Kim KY, Kim SS and Cheon HG: Differential anti-proliferative actions of peroxisome proliferator-activated receptor-gamma agonists in MCF-7 breast cancer cells. Biochem Pharmacol 72: 530-540, 2006.

10. Buttram VC Jr and Reiter RC: Uterine leiomyomata: etiology, symptomatology, and management. Fertil Steril 36: 433-445, 1981.

11. Cramer SF, Marchetti C, Freedman J and Padela A: Relationship of myoma cell size and menopausal status in small uterine leiomyomas. Arch Pathol Lab Med 124: 1448-1453, 2000.

12. Chiaffarino F, Parazzini F, La Vecchia C, Chatenoud L, Di Cintio E and Marsico S: Diet and uterine myomas. Obstet Gynecol 94: 395-398, 1999.

13. Chiaffarino F, Parazzini F, La Vecchia C, Marsico S, Surace M and Ricci E: Use of oral contraceptives and uterine fibroids: results from a case-control study. Br J Obstet Gynaecol 106: 857-860, 1999.

14. Chiaffarino F, Parazzini F, La Vecchia C, Ricci E and Crosignani PG: Oral contraceptive use and benign gynecologic conditions. A review. Contraception 57: 11-18, 1998.

15. Clemons $M$ and Goss P: Estrogen and the risk of breast cancer. N Engl J Med 344: 276-285, 2001.

16. Ikeda $\mathrm{K}$ and Inoue $\mathrm{S}$ : Estrogen receptors and their downstream targets in cancer. Arch Histol Cytol 67: 435-442, 2004.

17. Marshall LM, Spiegelman D and Barbieri RL: Variation in the incidence of uterine leiomyoma among premenopausal women by age and race. Obstet Gynecol 90: 967-973, 1997.

18. Marshall LM, Spiegelman D and Goldman MB: A prospective study of reproductive factors and oral contraceptive use in relation to the risk of uterine leiomyomata. Fertil Steril 70: 432-439, 1998.

19. Marshall LM, Spiegelman D and Manson JE: Risk of uterine leiomyomata among premenopausal women in relation to body size and cigarette smoking. Epidemiology 9: 511-517, 1998.

20. Parazzini F, Negri E, La Vecchia C, Chatenoud L, Ricci E and Guarnerio P: Reproductive factors and risk of uterine fibroids. Epidemiology 7: 440-442, 1996.

21. Parazzini F, Negri E, La Vecchia C, Fedele L, Rabaiotti M and Luchini L: Oral contraceptive use and risk of uterine fibroids. Obstet Gynecol 79: 430-433, 1992.

22. Parazzini F, Negri E and La Vecchia C: Uterine myomas and smoking. Results from an Italian study. J Reprod Med 41: 316-320, 1996. 
23. Adamson GD: Treatment of uterine fibroids: current findings with gonadotropin-releasing hormone agonists. Am J Obstet Gynecol 166: 746-751, 1992.

24. Gao Z, Matsuo H, Wang Y, Nakago S and Maruo T: Upregulation by IGF-I of proliferating cell nuclear antigen and Bcl-2 protein expression in human uterine leiomyoma cells. J Clin Endocrinol Metab 86: 5593-5599, 2001.

25. Guzeloglu-Kayisli O, Kayisli UA, Al-Rejjal R, Zheng W, Luleci G and Arici A: Regulation of PTEN (phosphatase and tensin homolog deleted on chromosome 10) expression by estradiol and progesterone in human endometrium. J Clin Endocrinol Metab 88: 5017-5026, 2003.

26. Mutter GL, Lin MC, Fitzgerald JT, Kum JB and Eng C: Changes in endometrial PTEN expression throughout the human menstrual cycle. J Clin Endocrinol Metab 85: 2334-2338, 2000.

27. Niswender KD, Gallis B, Blevins JE, Corson MA, Schwartz MW and Baskin DG: Immunocytochemical detection of phosphatidylinositol 3-kinase activation by insulin and leptin. J Histochem Cytochem 51: 275-283, 2003.
28. Gericke A, Munson M and Ross AH: Regulation of the PTEN phosphatase. Gene 374: 1-9, 2006.

29. Vazquez F, Grossman SR, Takahashi Y, Rokas MV, Nakamura N and Sellers WR: Phosphorylation of the PTEN tail acts as an inhibitory switch by preventing its recruitment into a protein complex. J Biol Chem 276: 48627-48630, 2001.

30. Myers MP, Pass I and Batty IH: The lipid phosphatase activity of PTEN is critical for its tumor supressor function. Proc Natl Acad Sci USA 95: 13513-13518, 1998

31. Rosen ED and Spiegelman BM: PPARgamma: a nuclear regulator of metabolism, differentiation, and cell growth. J Biol Chem 276: 37731-37734, 2001.

32. Koeffler HP: Peroxisome proliferator-activated receptor gamma and cancers. Clin Cancer Res 9: 1-9, 2003.

33. Patel L, Pass I, Coxoo P, Downes CP, Smith SA and Macphee CH: Tumor suppressor and anti-inflammatory actions of PPARgamma agonists are mediated via upregulation of PTEN. Curr Biol 11: 764-768, 2001. 